\title{
ANALISIS MARGIN PEMASARAN WORTEL DI DESA SINISIR KECAMATAN MODOINDING
}

\author{
Finka Erika Dongi \\ Noortje M. Benu \\ Grace Adonia Josefina Rumagit
}

Naskah diterima melalui Website Jurnal Ilmiah agrisosioekonomi@unsrat.ac.id

: Rabu, 23 Oktober 2019

Disetujui diterbitkan

: Minggu, 27 Oktober 2019

\begin{abstract}
This study aims to determine marketing patterns, calculate the amount of margins, profit and marketing costs as well as farmer's share in Sinisir Village, Modoinding Sub-district, Minahasa Regency. This research was conducted from June to August 2018. The data used in this study are primary and secondary data. Primary data were collected from interviews based on a list of questions prepared previously on 14 respondents consisting of 10 farmers from Sinisir Village, 1 collecting trader from Tompaso Baru Dua Village, 2 retailers from Tompaso Baru Dua Village and in Karombasan Village, 1 big trader from Sinisir Village, Modoinding District. Whereas secondary data was obtained from the Sinisir Village Office of Modoinding District from local bookstores and from the internet. From the internet through google searching in the form of books and theses from other universities. The results showed that there were four forms of marketing channels in Sinisir Village, Modoinding District, namely: (I) Farmers - Consumers; (II) Farmers - Retailers - Consumers; (III) Farmers - Collector Traders Retailers Traders - Consumers; IV) Farmers - Wholesalers. The carrot marketing channel which produced the highest cost, margin and marketing profit in marketing channel II was Rp 5,429 per kilogram, Rp 6,000 per kilogram, Rp 571 per kilogram. The highest farmer's share in marketing channel 1 is 100 percent. ${ }^{*}$ eprm*
\end{abstract}

Keywords: marketing margins; carrot; farmer's share

\begin{abstract}
ABSTRAK
Penelitian ini bertujuan untuk mengetahui pola pemasaran, menghitung besarnya margin, keuntungan dan biaya pemasaran serta bagian yang diterima petani (farmer's share) di Desa Sinisir Kecamatan Modoinding Kabupaten Minahasa. Penelitian ini dilaksanakan sejak bulan Juni sampai Agustus tahun 2018. Data yang digunakan dalam penelitian ini adalah data primer dan sekunder. Data primer dikumpulkan dari wawancara berdasarkan daftar pertanyaan yang telah dipersiapkan sebelumnya pada 14 responden yang terdiri atas 10 petani dari Desa Sinisir, 1 pedagang pengumpul dari Desa Tompaso Baru Dua, 2 orang pedagang pengecer dari Desa Tompaso Baru Dua dan di Kelurahan Karombasan, 1 orang pedagang besar dari Desa Sinisir Kecamatan Modoinding. Sedangkan data sekunder diperoleh dari Kantor Desa Sinisir Kecamatan Modoinding dari toko buku lokal dan dari internet. Dari internet melalui google searching berupa buku dan skripsi dari universitas lain. Hasil penelitian menunjukkan bahwa ada empat bentuk saluran pemasaran di Desa Sinisir Kecamatan Modoinding yaitu: (I) Petani - Konsumen Akhir; (II) Petani - Pedagang Pengecer - Konsumen; (III) Petani - Pedagang Pengumpul - Pedagang Pengecer -Konsumen; IV) Petani - Pedagang Besar. Saluran pemasaran wortel yang menghasilkan biaya, margin, dan keuntungan pemasaran tertinggi pada saluran pemasaran II yaitu Rp 5.429 per kilogram, Rp 6.000 per kilogram, Rp 571 per kilogram. Bagian yang diterima petani (farmer's share) tertinggi pada saluran pemasaran I yaitu sebesar 100 persen. ${ }^{*}$ eprm* $^{*}$
\end{abstract}

Kata kunci:; margin pemasaran; wortel; bagian yang diterima petani (farmer's share) 


\section{PENDAHULUAN}

\section{Latar Belakang}

Sektor pertanian merupakan sektor strategis dalam pembangunan nasional. Peran sektor pertanian dalam memacu perekonomian dapat dilihat lebih luas terutama dalam konteks mendistribusikan hasil-hasil pembangunan kepada masyarakat diwilayah pedesaan. Sektor pertanian dituntut untuk berperan dalam perekonomian melalui pembentukan produk domestik bruto, perolehan devisa, penyediaan pangan dan bahan baku industri, pengentasan kemiskinan, penyediaan lapangan kerja, dan peningkatan pendapatan masyarakat. Selain kontribusi langsung, sektor pertanian juga memiliki kontribusi secara tidak langsung berupa dampak berganda (multiplier effect) yaitu keterkaitan input-output antara industri, konsumsi, dan investasi (Rorenku, 2005 dalam Rilia, 2014).

Peningkatan pendapatan petani harus ditunjang dengan dilakukan berdasarkan pasar untuk memenuhi kebutuhan pasar domestik dan luar negeri yang terus meningkat akan hasil pertanian yang unggul dan meningkatkan pangsa pasar hasil pertanian dalam pasar internasional dan memiliki komoditas yang bernilai jual serta tingkat produksi yang tinggi.

Pendapatan petani sangat dipengaruhi oleh pemasaran hasil produksinya dan harga yang berlaku, dimana pemasaran yang kurang efisiensi adalah kecilnya bagian yang diterima petani dari harga yang dibayar konsumen akhir.

Wortel adalah tumbuhan biennial (siklus hidup 12-24 bulan) yang menyimpan karbohidrat dalam jumlah besar untuk tumbuhan tersebut berbunga pada tahun kedua. Sayuran ini terkenal dengan kandungan gizinya. Selain itu tanaman ini dapat dijadikan alat kosmetik dan obat-obatan sehingga tanaman ini banyak digemari oleh masyarakat Indonesia.

Komoditi hortikultura merupakan komoditi yang mempunyai kedudukan yang penting dalam masyarakat maupun perekonomian negara. Pengembangan produksi hortikultura sebagai sumber gizi ditingkatkan untuk pertumbuhan manusia di Indonesia yang sehat dan berkembang tinggi dalam memikul tugas pembangunan yang semakin berat (Sudiyono 2002). Luas Tanam, Luas Panen dan Produksi Wortel per desa di Kecamatan Modoinding Tahun 2017 dapat dilihat pada Tabel 1.
Tabel 1. Luas Tanam, Luas Panen dan Produksi Wortel per desa di Kecamatan Modoinding Tahun 2017

\begin{tabular}{lccc}
\hline \multicolumn{1}{c}{ Desa } & $\begin{array}{c}\text { Luas Tanam } \\
(\mathrm{Ha})\end{array}$ & $\begin{array}{c}\text { Produktivitas } \\
\text { (Ton) }\end{array}$ & $\begin{array}{c}\text { Total } \\
\text { Produksi }\end{array}$ \\
\hline Mokobang & 10 & 150 & 160 \\
Wulurmaatus & 20 & 300 & 320 \\
Palelon & 25 & 375 & 400 \\
Makaaruyen & 30 & 450 & 480 \\
Pinasungkulan & 40 & 600 & 640 \\
Pinasungkulan Utara & 50 & 750 & 800 \\
Linelean & 25 & 375 & 400 \\
Sinisir & 125 & 1875 & 2000 \\
Kakenturan & 30 & 450 & 480 \\
Kakenturan Barat & 25 & 375 & 400 \\
\hline Jumlah & 380 & 5700 & 5920 \\
\hline Sumber : BP3K Kecamatan Modoinding, 2017
\end{tabular}

\section{Deskripsi Umum Tanaman Wortel}

Wortel merupakan jenis sayuran yang menyehatkan untuk tubuh manusia sehingga perlu dibudidayakan lebih banyak lagi untuk kesejahteraan dan memenuhi kebutuhan manusia. Selain enak dan digemari oleh banyak masyarakat sebagai bahan untuk membuat aneka macam masakan, wortel pula dapat digunakan sebagai bahan kosmetik serta berkhasiat obat sebagai penyembuh berbagai macam penyakit, karena didalam umbi wortel mengandung senyawa beta karoten yang dapat menimbulkan kekebalan tubuh terhadap penyakit (Cahyono 2002). wortel diklasifikasikan sebagai berikut :

$\begin{array}{ll}\text { Kingdom } & \text { : Plantae } \\ \text { Divisi } & \text { : Spermatophyta } \\ \text { Kelas } & \text { : Dicotyledoneae } \\ \text { Ordo } & \text { : Umbelliferales } \\ \text { Family } & \text { : Umbelliferae } \\ \text { Genus } & \text { : Daucus } \\ \text { Spesies } & \text { : Daucus carota } \mathrm{L} .\end{array}$

\section{Fungsi-Fungsi Pemasaran}

Menurut Ginting (2006) terdapat tiga tipe fungsi pemasaran, yaitu :

1. Fungsi pertukaran, yaitu semua tindakan untuk memperlihatkan pemindahan hak milik atas barang dan jasa (fungsi penjualan dan fungsi pembelian)

2. Fungsi fisik, yaitu semua tindakan atau perlakuan terhadap barang, sehingga memperoleh kegunaan tempat dan waktu (fungsi penyimpanan dan fungsi pengangkutan)

3. Fungsi fasilitas, yaitu senua tindakan yang menunjang kelancaran pelaksanaan fungsi pertukaran dan fisik (fungsi standardisasi, fungsi penanggungan resiko, fungssi pembiayaan, dan fungsi informasi pasar). 


\section{Rumusan Masalah}

Berdasarkan latar belakang yang diuraikan, maka permasalahan yang akan dikaji dalam penelitian ini yaitu bagaimana margin pemasaran komoditi wortel?

\section{Tujuan Penelitian}

1. Mengetahui ada berapa saluran pemasaran di Desa Sinisir Kecamatan Modoinding.

2. Mengetahui besarnya biaya, margin dan keuntungan tertinggi di tiap saluran.

3. Mengetahui farmer's share tertinggi di tiap saluran.

\section{Manfaat Penelitian}

1. Manfaat dalam penelitian ini yaitu, untuk memberikan informasi bagi petani buah salak di Desa Pangu Dua tentang pemasaran buah salak

2. Sebagai sumber informasi bagi peneliti yang selanjutnya, dalam memberikan masukan untuk penelitian lanjutan.

\section{METODE PENELITIAN}

\section{Tempat dan Waktu Penelitian}

Penelitian ini dilaksanakan pada bulan Mei 2018. Tempat penelitian dilaksanakan di Desa Sinisir Kecamatan Modoinding Kabupaten Minahasa Selatan.

\section{Metode Pengumpulan Data}

Data yang digunakan dalam penelitian ini adalah data primer dan data sekunder. Data primer diperoleh melalui wawancara langsung dengan petani wortel, pedagang pengumpul, pedagang besar dan pedagang pengecer. Data sekunder diperoleh dari instansi-instansi yang terkait dalam penelitian ini seperti BP3K Kecamatan Modoinding dan Kantor Kecamatan Modoinding.

\section{Metode Pengambilan Sampel}

Penentuan lokasi penelitian dilakukan secara sengaja (purposive sampling). Jumlah responden yang diambil adalah sebanyak 10 petani wortel. Pedagang pengecer 2, pedagang pengumpul 1, dan pedagang besar 1 dengan cara Snowball Sampling, dimana sampel diperoleh berdasarkan informasi dari responden pertama yaitu petani wortel, kemudian ditelusuri hingga ke konsumen akhir.

\section{Konsep Pengukuran Variabel}

Variabel - variabel yang akan diukur dalam penelitian ini, yaitu :

1. Karakteristik Responden :

a. Umur

b. Tingkat Pendidikan

c. Jumlah Tanggungan

d. Lama Berusahatani

2. Karakteristik Usahatani Buah Salak yang meliputi :

a. Luas lahan (Ha)

b. Jumlah produksi buah salak dalam satu kali panen $(\mathrm{Kg} / \mathrm{ha})$

3. Harga ditingkat petani yaitu penerimaan harga petani buah salak dari lembaga pemasaran $(\mathrm{Rp} / \mathrm{kg})$

4. Harga dtingkat pedagang pengumpul adalah harga yang diterima dari pedagang pengumpul dari hasil penjualan kepada konsumen $(\mathrm{Rp} / \mathrm{kg})$

5. Harga ditingkat konsumen yaitu harga yang diterima konsumen dari penjualan di tingkat pengecer $(\mathrm{Rp} / \mathrm{kg})$

6. Lembaga pemasaran dalam memasarkan buah salak

a. Biaya pengepakan/pengemasan $(\mathrm{Rp})$

b. Biaya pengangkutan/transportasi (Rp)

c. Biaya tenaga kerja (Rp)

d. Biaya Retribusi (Rp)

\section{Metode Analisis Data}

Analisis data yang digunakan dalam penelitian ini adalah :

1. Margin Pemasaran.

Analisis margin pemasaran menggunakan rumus sebagai berikut :

$$
\mathbf{M r}=\mathbf{P r}-\mathbf{P f}
$$

Dimana :

$\mathrm{Mr}=$ Marjin pemasaran

$\operatorname{Pr}=$ Harga jual ditingkat pedagang/pengecer

$\mathrm{Pf}=$ Harga jual ditingkat petani

2. Biaya.

Analisis biaya menggunakan rumus sebagai berikut :

Dimana :

$$
\text { Bp }=\text { Bp1+Bp2+Bp3...Bpn }
$$

$$
\begin{aligned}
\mathrm{Bp} & =\text { Biaya Pemasaran } \\
\mathrm{i} & =1,2,3 \ldots . \mathrm{n} \\
\mathrm{n} & =\text { Jumlah Lembaga Pemasaran }
\end{aligned}
$$




\section{Farmer Share}

Analisis farmer share menggunakan rumus sebagai berikut :

Dimana :

$$
\text { Fs } \frac{P f}{P r} x 100
$$

Fs = Bagian yang diterima petani

Pf $=$ Harga ditingkat Petani $(\mathrm{Rp} / \mathrm{kg})$

$\operatorname{Pr}=$ Harga ditingkat Konsumen $(\mathrm{Rp} / \mathrm{kg})$

\section{Keuntungan}

Analisis keuntungan menggunakan rumus sebagai berikut :

Dimana :

$$
\mathbf{P}=\mathbf{M}-\mathbf{C}
$$

$\mathrm{P}=$ Keuntungan Margin $(\mathrm{Rp} / \mathrm{Kg})$

$\mathrm{M}=$ Harga di tingkat pedagang $(\mathrm{Rp} / \mathrm{kg})$

$\mathrm{C}=$ Biaya pemasaran $(\mathrm{Rp} / \mathrm{kg})$

\section{HASIL DAN PEMBAHASAN}

\section{Deskripsi Lokasi Penelitian}

Kecamatan Modoinding merupakan salah satu kecamatan yang berada di Kabupaten Minahasa Selatan yang terdiri dari 10 (sepuluh) desa yang seluruhnya berada diketinggian lebih dari 1.000 meter diatas permukaan laut dengan batas-batas wilayah sebagai berikut :

- Sebelah Utara berbatasan dengan Kecamatan Maesaan

- Sebelah Selatan berbatasan dengan Kabupaten Bolaang Mongondow

- Sebelah Timur berbatasan dengan Kabupaten Bolaang Mongondow

- Sebelah Barat berbatasan dengan Kabupaten Bolaang Mongondow

Kecamatan Modoinding masing-masing dipimpin oleh seorang Camat, sementara desadesa yang ada dikecamatan Modoinding dipimpin oleh seorang kepala desa (Hukum Tua).

\section{Kararakteristik Responden Petani}

\section{Umur Petani}

Responden dilokasi penelitian memiliki umur berkisar $25 \quad-70$ tahun, dengan pengalaman berusaha tani antara 5 sampai 50 tahun dapat dilihat pada Tabel 2.
Tabel 2. Jumlah Persentase Petani Responden Berdasarkan

\begin{tabular}{|c|c|c|c|}
\hline No & Kelompok Umur (Tahun) & Jumlah Petani & Persentase $(\%$ \\
\hline 1. & $25-30$ & 2 & 20,00 \\
\hline 2. & $31-36$ & 2 & 20,00 \\
\hline 3. & $37-42$ & 1 & 10,00 \\
\hline 4. & $43-48$ & 1 & 10,00 \\
\hline 5. & $49-54$ & 1 & 10,00 \\
\hline 6. & $55-60$ & 1 & 10,00 \\
\hline 7. & $61-66$ & 1 & 10,00 \\
\hline \multirow[t]{2}{*}{8.} & $67-70$ & 1 & 10,00 \\
\hline & Jumlah & 10 & 100 \\
\hline
\end{tabular}
Kelompok Umur di Desa Sinisir

Tabel 1 menunjukkan bahwa petani responden pada kelompok umur 25-30 tahun dan 31-36 tahun memiliki jumlah sama banyak yaitu 2 petani atau sebesar $20 \%$. Dalam menjalankan usahatani wortel dibutuhkan tenaga yang besar karena topografi lahan pertanian wortel yang berbukit dan perawatan tanaman wortel harus dilakukan secara intensif. Petani yang berada pada umur produktif pada umumnya bersikap lebih terbuka terhadap informasi maupun teknologi terkini yang berkaitan dengan usahatani wortel, sehingga diharapkan petani mampu mengembangkan usahataninya untuk meningkatkan penerimaan usahataninya.

\section{Tingkat Pendidikan Petani}

Pendidikan merupakan faktor yang sangat penting untuk meningkatkan sumber daya manusia, karena pendidikan dapat meningkatkan intelektual seseorang sehingga akan lebih mudah menerima dan memilah informasi-informasi untuk mengimplementasikan kedalam usahataninya, dari penggunaan faktor-faktor produksi yang efisien sampai pada pemasaran produk yang lebih menguntungkan bagi usahataninya. Berikut jumlah petani di Desa Sinisir Kecamatan modoinding menurut tingkat

\begin{tabular}{|c|c|c|c|}
\hline No & Tingkat Pendidikan & Jumlah Petani & Persentase (\%) \\
\hline 1. & $\mathrm{SD}$ & 3 & 30,00 \\
\hline 2. & SMP & 4 & 40,00 \\
\hline 3. & SMA & 3 & 30,00 \\
\hline 4. & S1 & - & - \\
\hline & Jumlah & 10 & 100 \\
\hline
\end{tabular}
pendidikan yang terangkum pada Tabel 3 .

Tabel 3 menunjukkan bahwa Tingkat pendidikan tertinggi berada pada tingkat pendidikan SMP yaitu sebanyak 4 petani responden atau sebesar 40,00\%. Maka dapat dikatakan bahwa tingkat pendidikan petani wortel sudah cukup baik. 


\section{Pengalaman Bertani}

Keberhasilan usahatani wortel tidak terlepas dari pengalaman petani dalam berusahatani wortel. Semakin lama usahatani wortel yang dilakukan oleh petani mengindikasikan bahwa petani telah melalui berbagai macam keadaan dalam menjalankan usahataninya. Pengalaman yang lalu merupakan refrensi bagi petani untuk berusahatani dimasa yang akan datang, baik dalam usahatani wortel maupun pemasarannya. Data mengenai pengalaman berusahatani dapat dilihat pada Tabel 4 .

Tabel 4. Jumlah dan Persentase Petani Responden Pengalaman

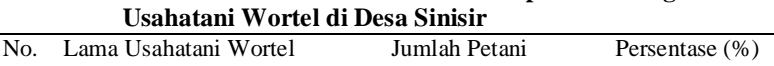

\begin{tabular}{llcr} 
No. & $\begin{array}{l}\text { Lama Usahatani Wortel } \\
\text { (Tahun) }\end{array}$ & Jumlah Petani & \\
\hline 1. & $5-15$ & 2 & 20,00 \\
2. & $16-26$ & 2 & 20,00 \\
3. & $27-37$ & 2 & 20,00 \\
4. & $38-48$ & 3 & 30,00 \\
5. & $49-59$ & 1 & 10,00 \\
\hline & Jumlah & 10 & 100 \\
\hline Sumber : Data Primer yang Diolah, 2018 &
\end{tabular}

Tabel 4 diketahui bahwa sebagian besar petani telah menjalankan usahatani wortel selama 38-48 tahun yaitu sebanyak 3 petani atau sebesar $30 \%$, sedangkan yang telah menjalankan usahatani wortel selama 5-15 tahun yaitu sebanyak 2 petani atau $20 \%, 16-26$ yaitu sebanyak 2 petani atau 20\%, 27-37 tahun yaitu 2 petani atau $20 \%$ memiliki jumlah petani responden yang sama banyak, kemudian diikuti dengan jumlah petani terkecil yaitu 49-59 tahun yang memiliki umur 50 tahun sebanyak 1 petani atau $10 \%$. Penduduk Desa Sinisir Kecamatan Modoinding pada umumnya telah lama menjalankan usahatani wortel ini dan bahkan sudah menjadi mata pencaharian.

\section{Luas Lahan}

Luas lahan merupakan salah satu faktor produksi yang penting dalam usahatani. Luas lahan tanam berpengaruh pada jumlah produksi wortel yang akan dihasilkan serta pendapatan yang akan diperoleh petani. Berdasarkan hasil penelitian, diperoleh data jumlah petani responden berdasarkan luas lahan tanam usahatani wortel dapat dilihat pada Tabel 5.

Tabel 5. Jumlah dan Persentase Petani Responden Berdasarkan Berdasarkan Luas Lahan Tanam Usahatani Wortel di Desa Sinisir

\begin{tabular}{llcr}
\hline No. & Luas Lahan Tanam & Jumlah Petani & Persentase (\%) \\
& Wortel $(\mathrm{kg})$ & & \\
\hline 1. & 0,35 & 5 & 50,00 \\
2. & 0,5 & 2 & 20,00 \\
3. & 0,70 & 3 & 30,00 \\
\hline & Jumlah & 10 & 100 \\
\hline
\end{tabular}

Agri-Sosioekonomi: 
2. Pedagang Pengumpul

Pedagang pengumpul merupakan pedagang yang melakukan pengumpulan hasil produksi petani yang selanjutnya dijual kembali kepada pedagang pengecer atau langsung ke konsumen akhir. Pedagang pengumpul di Desa Tompaso Baru Dua membeli langsung wortel dari petani sehingga petani tidak mengeluarkan biaya transportasi. Pedagang pengecer di Tompaso Baru Dua menjual kembali langsung wortel ke pedagang pengecer di Tompaso Baru Dua dengan di datangi langsung oleh pedagang pengecer sehingga pedagang pengumpul tidak mengeluarkan biaya transportasi, kemudian selain dijual ke pedagang pengecer juga dijual langsung ke konsumen akhir di Desa Tompaso Baru Dua. Dalam satu kali pembelian pedagang pengumpul membeli wortel pada petani sebanyak $200 \mathrm{~kg}$.

3. Pedagang Besar

Pedagang besar adalah pedagang yang mengumpulkan atau membeli semua hasil wortel petani Desa Sinisir dalam satu kali panen dan dijual kembali ke Ternate dan Ambon yang sebelumnya telah terjadi kesepakatan antar pedagang besar dan pembeli di Ternate dan Ambon.

4. Konsumen

Konsumen merupakan orang yang membeli langsung wortel dari pedagang pengecer atau lembaga pemasaran lainnya untuk dikonsumsi.

\section{Saluran Pemasaran}

Saluran pemasaran adalah rangkaian lembaga pemasaran yang dilalui barang dalam penyalurannya dari produsen ke konsumen. Saluran pemasaran dapat dipilih seara bebas artinya lembaga pemasaran dapat memilih langsung saluran pemasaran mana yang lebih menguntungkan.

Berdasarkan penelitian yang dilakukan di

Desa Sinisir Kecamatan Modoinding, maka saluran pemasarannya adalah sebagai berikut :

1. Petani - Konsumen Akhir

Pada saluran ini petani juga bertindak sebagai pedagang pengecer yang menjual langsung produknya ke konsumen. Sistem pemasarannya yaitu petani menjual langsung hasil panen wortel dari kebun melalui tempat tinggal petani itu sendiri. Saluran pemasaran ini disebut Saluran Tingkat Nol.
2. Petani - Pedagang Pengecer - Konsumen

Pada saluran ini pedagang pengecer di Kelurahan Karombasan membeli wortel yang dibawa langsung oleh petani Desa Sinisir, dari Desa Sinisir dibawah ke pedagang pengecer pasar Karombasan, kemudian dijual kembali ke konsumen akhir melalui pasar di Kelurahan Karombasan. Saluran pemasaran ini disebut Saluran Tingkat Satu yaitu hanya terdapat satu perantara.

3. Petani - Pedagang Pengumpul - Pedagang Pengecer -Konsumen

Pada saluran ini, pedagang pengumpul di Desa Tompaso Baru Dua membeli langsung wortel dari rumah petani di Desa Sinisir kemudian menjualnya kembali ke pedagang pengecer dengan didatamgi langsung oleh pedagang pengecer di Desa Tompaso Baru Dua dan dijual kembali ke konsumen akhir melalui pasar di Desa Tompaso Baru Dua. Saluran pemasaran ini disebut Saluran Pemasaran Tingkat Dua yaitu terdpat dua perantara.

4. Petani - Pedagang Besar

Pada saluran ini, pedagang besar di Desa Sinisir membeli langsung hasil panen wortel dari petani Desa Sinisir. Sistim pemasarannya pedagang besar menjual wortel yang dibeli langsung dari petani ke Ternate dan Ambon melalui Pelabuhan Laut Manado.

\section{Margin Pemasaran dan Farmer's Share pada Saluran Pemasaran I}

Rata-rata biaya, keuntungan, margin pemasaran dan farmer's share pada saluran pemasaran I dapat dilihat pada Tabel 6.

Tabel 6. Komponen Biaya, Keuntungan, Margin Pemasaran dan Farmer's Share Wortel Pada Saluran I

\begin{tabular}{lcr}
\hline Komponen Biaya Petani & Harga $(\mathrm{Rp} / \mathrm{Kg})$ & Share $(\%)$ \\
\hline Harga jual & 5.000 & 100 \\
Biaya Pemasaran & & \\
1. Pengangkutan & 4,05 & 0,09 \\
2. Biaya T.K & 4,05 & 0,09 \\
3. Pengepakan & 55,56 & 1,12 \\
4. Pengemasan & 0,54 & 0,02 \\
\hline Total Biaya & 64,2 & 1,28 \\
\hline Harga Beli Konsumen Akhir & 5.000 & 100 \\
\hline Farmer's Share (\%) &
\end{tabular}

Tabel 6 menunjukkan bagian yang diterima petani adalah 100 persen. Rata-rata biaya pemasaran pada saluran pada saluran pemasaran I yaitu Rp. 64,2 atau 1,28 persen dengan perincian biaya antara lain pengangkutan 
dengan menggunakan sepeda motor (kalero), biaya tenaga kerja untuk 1 orang dalam sehari bekerja, pengepakan yaitu menggunakan 1 karung beras, dan pengemasan yang menggunakan kantong plastik. Saluran pemasaran ini petani menjual langsung hasil produksinya ke konsumen akhir di Desa Sinisir Kecamatan Modoinding melalui pasar atau tempat tinggal petani itu sendiri. Disini petani juga bersifat sebagai pedagang.

\section{Margin Pemasaran dan Farmer's Share pada Saluran Pemasaran II di pasar Karombasan}

Rata-rata biaya, keuntungan, margin pemasaran dan farmer's share pada saluran IV dapat dilihat pada Tabel 7.

\begin{tabular}{|c|c|c|}
\hline Komponen Biaya Petani & $\begin{array}{c}\text { Harga } \\
(\mathrm{Rp} / \mathrm{Kg})\end{array}$ & Share $(\%)$ \\
\hline \multicolumn{3}{|l|}{ Petani Wortel } \\
\hline Harga Jual & 12.000 & 66,67 \\
\hline \multicolumn{3}{|l|}{ Biaya Pemasaran } \\
\hline 1. Pengangkutan I & 333,34 & 1,86 \\
\hline 2. Pengangkutan II & $2.539,69$ & 14,11 \\
\hline 3. Pengepakan & 55,56 & 0,31 \\
\hline Total Biaya & 2.929 & 16,27 \\
\hline Keuntungan & -2.929 & $-16,27$ \\
\hline Margin & 0 & 0 \\
\hline Harga beli pedagang pengecer & 12.000 & 66,67 \\
\hline \multicolumn{3}{|l|}{ Pasar Karombasan } \\
\hline \multicolumn{3}{|l|}{ Biaya Pemasaran } \\
\hline 1. Pengemasan & 500 & 2,78 \\
\hline 2. Retribusi & 2.000 & 11,12 \\
\hline Total Biaya & 2.500 & 13,89 \\
\hline Keuntungan & 3.500 & 19,45 \\
\hline Margin & 6.000 & 33,34 \\
\hline Harga Jual Ke pedagang Pengecer & 18.000 & 100 \\
\hline Total Biaya Pemasaran & 5.429 & 30,16 \\
\hline Toal Keuntungan Pemasaran & 571 & 3,18 \\
\hline Total Margin Pemasaran & 6.000 & 33,34 \\
\hline Farmer's share & & 66,67 \\
\hline
\end{tabular}

Tabel 7 menunjukkan bahwa biaya yang dikeluarkan petani antara lain pengangkutan I yang mengangkut wortel dari kebun menggunakan motor atau kalero ke rumah petani sebesar Rp. 333,34 atau 1,86 persen, pengangkutan II yang mengangkut wortel dari rumah petani ke pasar karombasan menggunakan mobil pick up sebesar Rp. 2.539 atau 16,27 persen dan pengepakan dengan menggunakan karung beras sebesar Rp. 56 atau 0,31 persen.

Biaya pemasaran yang dikeluarkan pedagang pengecer antara lain pengemasan di dalamnya menggunakan kantong plastik dengan biaya sebesar Rp.500 atau 2,78 persen dan retribusi sebesar Rp. 2.000 atau 11,12 persen dalam sehari berdagang. Pada saluran pemasaran I hanya melalui lembaga pemasaran yaitu pedagang pengecer. Pedagang pengecer mendapatkan keuntungan sebesar Rp 3.500 atau 19,45 persen.

Hasil analisis menunjukkan margin pemasaran pada saluran II adalah $\mathrm{Rp} 6.000$ atau 33,34 persen, sedangkan bagian yang diterima petani (farmer's share) pada saluran pemasaran I yaitu 100 persen.

Margin Pemasaran dan Farmer's Share pada Saluran Pemasaran III dipasar Tompaso Baru Dua

Rata-rata biaya, keuntungan, margin pemasaran dan farmer's share pada saluran IV dapat dilihat pada Tabel 8.

Tabel 8. Komponen Biaya, Keuntungan, Margin Pemasaran dan Share Wortel pada Saluran Pemasaran III di pasar Tompaso Baru Dua

\begin{tabular}{lrr}
\hline Komponen Biaya Petani & \multicolumn{1}{c}{$\begin{array}{c}\text { Harga } \\
(\mathrm{Rp} / \mathrm{Kg})\end{array}$} & Share $(\%)$ \\
\hline Petani Wortel & & \\
Harga Jual & 5.000 & 50.00 \\
Pedagang Pengumpul & & \\
Harga Beli & 5.000 & 50.00 \\
Biaya Pemasaran & & 14,11 \\
$\quad$ Pengangkutan & 900 & 0,31 \\
Total Biaya & 250 & 16,27 \\
Keuntungan & 1.150 & $-16,27$ \\
Margin & 3.000 & 0 \\
Harga Jual Ke pedagang Pengecer & 8.000 & 66,67 \\
Ke Pengecer Pasar Tompaso Baru & & \\
\hline Pedagang Pengecer & & \\
Biaya Pemasaran & 111,12 & 2,78 \\
$\quad$ 1. Pengangkutan I & 2.000 & 11,12 \\
$\quad$ 2. Pengangkutan II & 333,34 & \\
$\quad$ 3. Biaya Pengemasan & 500 & \\
$\quad$ 4. Retribusi & 500 & \\
Total Biaya & $1.444,46$ & 13,89 \\
Keuntungan & 556 & 19,45 \\
Margin & 2.000 & 33,34 \\
\hline Harga Beli Konsumen Akhir & 10.000 & 100 \\
\hline Total Biaya Pemasaran & $2.594,46$ & 30,16 \\
\hline Total Keuntungan Pemasaran & $1.705,54$ & 3,18 \\
\hline Total Margin Pemasaran & 6.000 & 33,34 \\
\hline Farmer's share & & 66,67 \\
\hline Sumber : Data Primer yang Diolah, & \\
\hline
\end{tabular}

Sumber : Data Primer yang Diolah, 2018

Tabel 8 menunjukkan bahwa pada lembaga pemasaran pertama yaitu ditingkat pedagang pengumpul, harga beli wortel dari petani Rp. 5.000 per $\mathrm{kg}$ dan dijual kepedagang pengecer dengan harga Rp. 8.000 per kg. Total biaya pemasaran pada saluran pemasaran III yaitu sebesar Rp. 2.58,46 atau 25,94 persen. Total biaya pemasaran yang dikelurkan oleh pedagang pengumpul lebih sedikit yaitu Rp.900 atau 9,00 persen, dikarenakan pedagang pengecer langsung membeli wortel dari pedagang pengumpul sehingga biaya pengangkutan dari pedagang pengecer lebih banyak dibanding pedagang pengumpul. 
Pada lembaga pemasaran kedua yaitu ditingkat pedagang pengecer harga beli wortel dari pedagang pengumpul yaitu sebesar Rp. 8.000 per $\mathrm{kg}$ dan dijual ke konsumen akhir dengan harga Rp. 10.000 per $\mathrm{kg}$. Total biaya pemasaran pada tingkat pedagang pengecer yaitu sebesar Rp. 1.444,46 atau 14,46 persen.

Keuntungan yang diperoleh pedagang pengumpul sebesar Rp. 1.150 atau 11,50 persen, dan pedagang pengecer mendapatkan keuntungan sebesar Rp. 556 atau 5,56 persen, sehingga keuntungan seluruh pada saluran ini sebesar Rp. 1.705,54 atau 17,06 persen.

\section{Margin Pemasaran dan Farmer's Share pada Saluran Pemasaran IV}

Rata-rata biaya, keuntungan, margin pemasaran dan farmer's share pada saluran IV dapat dilihat pada Tabel 9.

Tabel 9. Komponen Biaya, Keuntungan, Margin Pemasaran dan Share Wortel Pada Saluran Pemasaran IV

\begin{tabular}{lrr}
\hline Komponen Biaya & $\begin{array}{r}\text { Harga } \\
(\mathrm{Rp} / \mathrm{Kg})\end{array}$ & $\begin{array}{r}\text { Share } \\
(\%)\end{array}$ \\
\hline (\%) & & \\
Petani & 2.100 & 77,78 \\
Harga Jual & & \\
\hline Pedagang Besar & 2.100 & 77,78 \\
Harga Beli & & \\
Biaya Pemasaran & 12 & 0,45 \\
$\quad$ 1. Pengangkutan I & 476,20 & 17,64 \\
$\quad$ 2. Pengangkutan II & 55,56 & 2,06 \\
$\quad$ 3. Pengepakan & 14,82 & 0,55 \\
$\quad$ 4. Biaya T. K & 9,53 & 0,35 \\
$\quad$ 5. Retribusi & 595,55 & 22,06 \\
Total Biaya & 4,45 & 0,16 \\
\hline Keuntungan & 600 & 22,23 \\
\hline Margin & 2.700 & 100 \\
\hline Harga Beli Konsumen & & \\
Akhir & & 77,78 \\
\hline Farmer's share
\end{tabular}

Sumber : Data Primer yang Diolah, 2018

Tabel 9 menunjukkan bahwa harga beli tingkat pedagang besar pada petani sebesar Rp. 2.100 per kg, dan harga jual ke pedagang di Ternate dan Ambon sebesar Rp. 2.700 per kg. Pedagang besar mengeluarkan biaya sebesar Rp. 595,55 atau 22,06 persen dikarenakan pedagang besar melakukan 2 kali pengangkutan sehingga mengeluarkan biaya yang lebih banyak. Pengangkutan pertama menggunakan motor atau (kalero) yang mengangkut hasil panen wortel dari kebun petani ke tempat tinggal pedagang besar dengan biaya Rp. 12 atau 0,45 persen, pengangkutan kedua menggunakan mobil besar atau truk untuk mengangkut wortel dari tempat tinggal pedagang besar ke Pelabuhan Laut Manado untuk dikirim ke Ternate dan Ambon dengan biaya Rp. 476,20 atau 17,64 persen. Keuntungan pemasaran yang diperoleh pada saluran pemasaran ini yaitu sebesar Rp. 4,45 atau 0,16 persen.

Total margin pemasaran pada saluran ini yaitu sebesar Rp. 600 atau 22,23 persen. Sedangkan bagian yang diterima oleh petani (farmer's share) sebesar 77,78 persen.

\section{Rangkuman Margin Pemasaran dan Farmer's Share Seluruh Saluran Pemasaran Wortel Di Desa Sinisir Kecamatan Modoinding}

Hasil penelitian yang terangkum pada Tabel 10 bahwa petani wortel di Desa Sinisir Kecamatan Modoinding dalam memasarkan hasil komoditinya mengandalkan pedagang pengumpul. Sehingga rata-rata harga jual ditingkat petani pada setiap saluran pemasaran adalah Rp. 5000 per kg. Harga jual wortel kemudian akan mengalami perubahan pada setiap saluran pemasaran setelah berada di tingkat pengumpul. Hal ini disebabkan pedagang pengumpul mendistribusikan wortel ke setiap lokasi-lokasi melibatkan lembagalembaga pemasaran (pedagang perantara) yaitu pedagang pengecer pasar Tompaso Baru, pasar Karombasan dan pedagang besar di Pelabuhan Laut Manado. Dengan adanya keterlibatan pedagang perantara jelas akan mempengaruhi harga jual wortel karena masing-masing pedagang perantara ingin memperoleh keuntungan pemasaran.

Harga jual, total biaya, keuntungan, margin pemasaran dan farmer's share pada setiap saluran pemasaran di Desa Sinisir Kecamatan Modoinding Kabupaten Minahasa Selatan terangkum pada Tabel 10. 
Tabel 10. Harga Jual, Total Biaya, Keuntungan, Margin Pemasaran dan Farmer's share pada setiap Saluran Pemasaran Wortel di Desa Sinisir

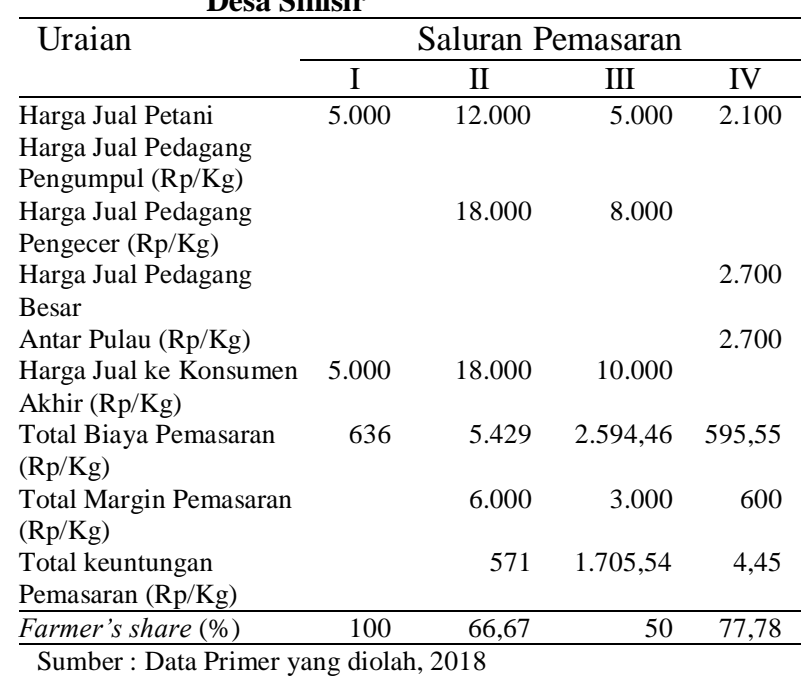

Tabel 10 menunjukkan bahwa margin pemasaran dan keuntungan pemasaran pada saluran pemasaran II menghasilkan nilai lebih tinggi yaitu masing-masing sebesar Rp. 6.000 per $\mathrm{kg}$ dan Rp. 571 per $\mathrm{kg}$ dengan total biaya Rp.5.429 per kg.

Kondisi tersebut memungkinkan Karena pada saluran pemasaran II melibatkan 1 pedagang perantara dimana dari petani menjual langsung kepada pedagang pengecer hingga kepada konsumen akhir. Pada saluran ini biaya pengangkutannya lebih besar karena petani membawa langsung kepada pedagang pengecer dengan total biaya Rp. 2.539 atau 14,11 persen.

Bagian yang diterima oleh petani (farmer's share) berhubungan negatif dengan margin pemasaran. Semakin besar margin pemasaran maka semakin kecil pula bagian yang diterima oleh petani. Berdasarkan uraian tersebut, maka dapat disimpulkan bahwa farmer's share tertinggi berada pada saluran I sebesar 100 persen, saluran II sebesar 50 persen, saluranIII sebesar 66,67 persen dan saluran IV sebesar 77,78 persen.

\section{KESIMPULAN DAN SARAN}

\section{Kesimpulan}

Berdasarkan hasil penelitian pemasaran wortel di Desa Sinisir Kecamatan Modoinding dapat disimpulkan sebagai berikut :
1. Pada pemasaran wortel di Desa Sinisir Kecamatan Modoinding terdapat 4 bentuk saluran pemasaran.

2. Saluran pemasaran wortel di Desa Sinisir Kecamatan Modoinding menghasilkan biaya, margin pemasaran dan keuntungan pemasaran tertinggi yaitu pada saluran pemasaran II sebesar Rp. 6.000 per kilogram dengan keuntungan sebesar Rp. 3.500 per kilogram dan total biaya sebesar Rp. 2.500 per kilogram. Hal ini disebabkan karena pada saluran pemasaran II melibatkan 1 pedagang perantara dimana dari petani menjual langsung kepada pedagang pengumpul ke pedagang pengecer hingga kepada konsumen akhir. Pada saluran ini biaya pengangkutannya lebih besar karena petani membawa langsung kepada pedagang pengecer, dan ditambah dengan jarak tempuh Wortel untuk memasarkan wortel cukup jauh serta kuantitas permintaan wortel dalam jumlah banyak.

3. Bagian yang diterima oleh petani (farmer's share) pada setiap saluran pemasaran wortel di Desa Sinisir Kecamatan Modoinding diperoleh bahwa farmer's share yang dihasilkan pada saluran pemasaran I memiliki nilai tertinggi yaitu sebesar 100 persen.

\section{Saran}

1. Para petani harus lebih lagi meningkatkan pemasaran wortel karena peluang pemasaran wortel baik di dalalm maupun di luar daerah memiliki prospek yang sangat baik untuk terus dikembangkan.

2. Harus adanya peran dari pemerintah untuk mendukung petani wortel dalam mengembangkan usahatani dan pemasaran wortel, khususnya dalam mengusahakan saran informasi bagi petani dalam kegiatan pemasaran wortel sehingga petani dapat menerima harga yang layak. 


\section{DAFTAR PUSTAKA}

Cahyono, B. 2002. Wortel "Teknik Budidaya dan Analisis Usaha Tani". Kanisius. Yogyakarta. Dari Saluran Pemasaran Yang Berasal Dari Desa Makaaruyen Kecamatan.

Ginting, Paham. 2006. Filsafat Ilmu dan Metode Penelitian, USU, Press. Medan. Modoinding (Skripsi). Jurusan Sosial Ekonomi Pertanian. Fakultas Pertanian Universitas Sam Ratulangi Manado.
Rilia, D. 2014. Perbandingan Tingkat Kesejahteraan Petani Kentang Dilihat

Sudiyono, A. 2002. Pemasaran Pertanian. Universitas Muhamadiyah Malang. 